\title{
An Experimental Study on the Structure of Living Nuclei in the Resting Stage
}

\author{
By \\ Namio Shinke \\ Botanical Institute, Kyoto Imperial University
}

The structure of the nucleus in the resting stage, an important problem in karyology not only from the mere morphological point of view but also from the genetical stand point, has been receiving special attention from investigators and has frequently been discussed from somewhat earlier days of karyological investigation, and as yet no unanimous conclusion has been attained. In the cases where the nucleus shows a distinct structure, the recent advances in this field of karyology seem to show that there is left little doubt on the view of the nucleus being a structure essentially composed of convoluted chromatin threads or chromonemata (ScHIWAGo, 1926, BĚLAŘ, 1930, TeleżyŃSKI, 1930, KUWAdA and NAKAMURA, 1933-34, FUJII and YASUI, 1936, KUWADA, 1936 and others). But the cases where the nuclei show indistinct structure with all possible grades up to the completely hyaline state have been also observed in both plants and animals. And a question is now raised as to whether there are structural differences of fundamental importance among these nuclei with different appearances. In the present paper some results of experiments we obtained concerning this question are reported.

\section{Material}

In the course of an experimental investigation with living nuclei, it was found that a great diversity in visibility of the structure of the healthy or intact nucleus is shown among different species and tissues and also according to the different physiological functions of the cells. The plants and animals or the tissues observed can be classified, referring to the presence or absence of the visible structure of the nucleus, into the following two groups.

a) With the nucleus showing no visible structure except for a nucleolus or nucleoli which are generally visible. ${ }^{1)}$ Solanum lycopersicum (hairs of the leaf), Primula malacoides (do.), Pharbitis Nil (do.), Elodea densa (epidermis of the leaf), Vicia faba (guard cells of open or closed stomata), Dahlia variabilis (do.), Tradescantia virginica (do.), Zebrina pendula (do.), and Rhoeo discolor (do.).

1) In certain plants small chromocenters are also visible. 
b) With the nucleus showing a structure more or less clearly visible. Cucurbita pepo var. Toonas (hairs of the leaf), Gynura aurantiaca (do.), Elodea densa (epidermis of the leaf), Vallisneria asiatica (do.), Hydrilla verticillata (do.), Allium cepa (inner epidermis of a scale of the bulb), Tradescantia reflexa (staminate hairs, epidermis of the young petals), T. virginica (hairs of the leaf, guard cells of half-open stomata), Ceratopteris thalictroides (guard cells of half-open stomata), Vicia faba (do.), Dahlia variabilis (do.), Sagittaria sinensis (do.), Zebrina pendula (do.), Rhoeo discolor (do.), and Triturus pyrrhogaster (intestinal epithelium).

In the experiments reported below these two kinds of nuclei mentioned above, the giant nuclei in the salivary gland of the larvae of Chironomus dorsalis and Drosophila virilis, and the first spermatocyte nuclei in Tryxalis nasuta were employed as material.

\section{Experiments and Results}

When intact nuclei belonging to one or the other of the groups given above are put in a hyper- or a hypotonic medium such as the solution of saccharose, glucose, urea, $\mathrm{NaCl}, \mathrm{KNO}_{3}$ or $\mathrm{CaCl}_{2}$ in different concentration, or RINGER's balanced solution in different dilutions, they undergo a marked change in visibility of the structure. A structure may become visible or disappear. These changes are reversible. That the changes are caused chiefly by the hydration or the dehydration ${ }^{1)}$ of the nuclear elements is evident from the fact ${ }^{2}$ that with a hypertonic medium 1) increase in the refractive index of the nucleus, 2) decrease in the nuclear volume, 3) stoppage of the Brownian movement and the streaming in the cytoplasm, and 4) occurrence of the plasmolysis (in the case of plant cells) are observed, while with a hypotonic medium the reverse changes take place. Thus it can be learned from the above that the homogeneity or the heterogeneity in appearance of the nuclear structure is chiefly due to the hydration grade of the nuclear elements. By the hydration and dehydration experiments the living nuclei can be classified into the following four types.

1) The terms "hydration" and "dehydration" are not used here in the strict colloid-chemical sense. They merely mean the "Wasseraufnahme" and "Wasserabnahme" respectively, each of which is accompanied with an increase or decrease in volume.

2) The special action of a neutral salt on the karyoplasm which has been studied by Strugger (1930), YamaHA and ISHII (1932), and Shigenaga (verbal information, briefly published in the paper by KuWADA, 1932) is neglesible in this case, because such an action is to be observed only in the case where the semipermeability is lost at least to a certain extent (cf. STROHMEYER, 1935). 
Type 1. The nucleus which belongs to this type exhibits no visible structure in its healthy condition. When it is observed in an isotonic solution (Fig. 1) ${ }^{11}$ it appears to be quite hyaline except for a nucleolus or nucleoli which are visible in the medium of liquid paraffin also. When it is dehydrated with a hypertonic solution, it comes to show a remarkable shrinkage which brings it into a completely homogeneous mass with no visible nucleoli (Fig. 2), while it shows little change in structure when treated with a hypotonic solution. The nucleus in this dehydrated state recovers its original swollen appearance, when transferred into the isotonic medium, without showing any heterogeneity during the process of swelling (Fig. 3 ). For the sake of convenience, this type of nucleus is designated here as the homogeneous nucleus I. Examples are found in the following plants: Elodea densa, Solanum lycopersicum, Primula malacoides and Pharbitis Nil in the tissues given above in brackets.

Type 2. In this type the healthy, intact nucleus is quite similar in its external appearance to the nucleus of the first type, any heterogeneity being not perceptible (Fig. 4) generally except for the nucleoli which are visible, but the use of a hypertonic solution can reveal the difference between the two types. While in Type 1 the nucleus shows no structure when put in a hypertonic solution, it shows chromonemata in the second type with more or less distinctness (Fig. 5). By the immersion in a more highly hypertonic solution, however, the chromonemata become obscure again, the nucleus becoming smaller and highly refractive, as shown in Fig. 6. We call the nucleus of this second type the homogeneous nucleus II, and the homogeneous nucleus which is obtainable by the dehydration of the nucleus of the second type or the homogeneous nucleus II we call the homogeneous nucleus III.2) Examples in which the homogeneous nucleus II is found: Elodea densa, ${ }^{31}$ Vicia faba (guard cells of closed stomata), Tradescantia virginica (do.), Zebrina pendula (do.), Dahlia variabilis (do.) and Rhoeo discolor (do.).

1) When definite concentrations of the plasmolysing agents are used, the nucleus and the cytoplasm show similar appearances to those presented by them when liquid paraffin is used as medium. These concentrations are taken as being isotonic in the present investigation.

2) The result we obtained in Elodea densa is quite in accord with that obtained by STROHMEYER (1935) in the same plant, though the author has made no account of the nuclei belonging to Types 1 and 3 in this plant.

Recently DoYLE and METZ (1935) have reported that the nucleus in the salivary gland of Sciara is optically homogeneous (the chromocenter excepted which is visible) in the isotonic RINGER's solution and heterogeneous in the hypertonic RINGER's. This result suggests that the nucleus in the salivary gland of this animal belongs probably to our Type 2 .

3 ) In the tissue already given above. 
It is of course hardly possible to draw a sharp line between Type 1 and Type 2. An intermediate type was observed incidentally in which the nucleus showed a cloudy or somewhat heterogeneous appearance in hypertonic solutions instead of the distinct image of chromonemata.

Type 3. In this third type the nucleus presents a heterogeneous appearance more or less distinctly in the normal condition as shown in Figs. 7 and 10. We call this type of the nucleus the heterogeneous nucleus (Type 3 ). In this type the results from the treatment with hypotonic solution are, as a rule, different in plant and animal cells (except the guard cells of stomata of some plants) owing to the fact that in the former the cell wall pressure prevents sufficient penetration of water into the cells to cause the disappearance of the nuclear structure.

a) In the plant cells, the nuclear structure disappears under the action of hypertonic solutions, and a remarkable shrinkage of the nucleus occurs at the same time (the homogeneous nucleus III, Fig. 8), 1) while it suffers, at most, only a little change in hypotonic solutions (Fig. 9). Examples: Ceratopteris thalictroides, Sagittaria sinensis, Gynura aurantiaca, Elodea densa, Hydrilla verticillata, Vallisneria asiatica, Allium cepa, Tradescantia reflexa and T. virginica (hairs of the leaf).

In the epidermis of Elodea densa and in the guard cells of closed stomata of Vicia faba, Tradescantia virginica, Zebrina pendula and some other plants, it is frequently observed that the nucleus exhibits a granular or mottled appearance more or less distinctly. In such nuclei the chromonemata are found not infrequently to be clearly visible when dehydrated. These nuclei may be regarded as an intermediate type between Types 2 and 3 .

It must be noted here also that the nuclei which belong to Types 1,2 and 3 are found even in a single leaf, for example, in the leaf of Elodea densa. In Fig. 1, the nuclei $a$ and $b$ belong to Type 1 and $d$ to Type 3 (Type 2 is not shown in this figure).

$b$ ) In the animal cells and the guard cells of half-open stomata the nuclear structure becomes invisible by both hyper- and hypotonic solutions in contrast with the case $a$ (Figs. 11 and 12). In the hypertonic solution, however, the nuclei considerably shrink (the homogeneous nucleus III), while in the hypotonic solution they swell (the homogeneous nucleus II). In Figs. 10-12, such nuclei of the

1) The disappearance of the nuclear structure by hypertonic solutions has been reported by some authors such as WADA, 1935, STROHMEYER, 1935, PÉterfi and KoJima, 1936, Nakamura (verbal information), and others. 
guard cells of a half-open stoma in Tradescantia virginica are exemplified in osmotically different solutions. In the case shown in Fig. 10 the stoma is put in the isotonic glucose solution, and the chromonemata are visible distinctly throughout the nucleus (the heterogeneous nucleus, Type 3) ; In the case of Fig. 11 it is put in a hypertonic glucose solution (the homogeneous nucleus III), and they are indistinct. The nuclei in the latter figure closely resemble in appearance those of fully-open stomata (compare Fig. 11 with Fig. 14). When these nuclei are brought back to a hypotonic solution, the chromonemata become visible again for a short time but soon disappear (the homogeneous nucleus II), while the nuclei of the subsidiary cells and those of the other epidermal cells show, in the same treatment, distinct chromonemata which never disappear in the ultimate result (case $a$, Fig. 12). Examples of this guard cell nuclear type: Vicia faba (guard cells of half-open stomata), Dahlia variabilis (do.), Tradescantia virginica (do.), Zebrina pendula (do.), Rhoeo discolor (do.), Triturus pyrrhogaster, Tryxalis nasuta, Chironomus dorsalis and Drosophila virilis.

The salivary gland chromosomes in the Chironomus larvae show the same behaviour towards the hydration and dehydration as that displayed by the chromonemata of the resting nucleus of Type $3, b$. These chromosomes are always found confined in the nucleus with one or two nucleoli. They are of the banded structure as are those observed in some other diptera larvae. The bands which are visible in the medium of liquid paraffin or the body fluid are of different thickness and are positive to FEULGEN's stain (cf. YASUI, 1935). In a concentrated RINGER's solution, the nuclei shrink and become homogeneous, both chromosomes and nucleoli being no longer visible. In a diluted RINGER's, on the contrary, the nuclei swell, markedly. The peripheral part of the nucleolus swells as well, and it becomes evident that in this peripheral region there are a number of minute particles of a somewhat angular shape. When this part of the nucleolus becomes enormously swollen, the particles appear to be set free and dispersed throughout the karyolymph. In this state, they generally display an active Brownian movement. The chromosomes also swell and become increased in volume, the outline being rendered more and more indistinct. In this stage of swelling, we can see only some small number of chromatic bands within the territory of the swollen chromosome. During the process of swelling some thick bands undergo a remarkable change in structure. They look as if they consisted of rows of minute, globular granules which 
are probably chromatic. ${ }^{1)}$ The general aspect of the bands now reminds us of pieces of pearl necklace arranged side by side. The chromatic granules show, not infrequently, a weak vibration movement. In Fig. 13, the pearl necklace structure of a chromatic band is shown (marked with an arrow). The further hydration taking place renders even these chromatic granules invisible, it being soon followed by the complete disappearance of the nucleolus or nucleoli. In this stage of swelling, the nucleus appears to be of a completely homogeneous structure except for a certain number of minute particles being visible frequently, particles which are derived from the peripheral part of the nucleolus. The ground substance of the nucleus is now fluid in its consistency as indicated by the active Brownian movement of these particles suspended in it. When these nuclei are gradually dehydrated with the isotonic RINGER's solution, the nucleolus and the chromosomes reappear. An especially interesting and important phenomenon in this reversible change is that the chromatic bands which have disappeared in the hypotonic solution generally reappear in the original positions in the chromosomes. This fact leads us to the conclusion that in the swollen chromosomes the chromatic substance has not been dispersed far beyond its territory even in the case where the nucleus appears to be an optically homogeneous fluid structure.

Type 4. The nucleus belonging to this type is found often in the guard cells of fully-open stomata of Vicia faba, Tradescantia virginica, Zebrina pendula and Rhoeo discolor. As has been reported by WEBER (1927), the nucleus in a fully-open stoma is highly refractive and often shows an uneven contour (Fig. 14). The chromonemata are obscurely visible in a liquid paraffin medium (the homogeneous nucleus III). They become distinct in a hypotonic solution, but in a hypertonic solution no change is exhibited (Fig. 15). In the former solution, they are again rendered obscure by a prolonged immersion.2) The nucleus is finally of a homogeneous structure, but now appear to be less light refractive than before the experiment. It resembles very much in appearance that found in a closed stoma (the homogeneous nucleus II-Fig. 16). It may be concluded, therefore, that the homogeneity of the nucleus in this fourth type is only

1) In the salivary gland nucleus of Sciara, DOYLE and Metz (1935) and METz (1935) have reported that the granular structure of the chromatic band is visible only in degeneration or shrinkage of the nucleus. According to the result we obtained these chromatic granules are observed at a certain period during the process of swelling of the chromosomes or shrinkage of swollen chromosomes.

2) This change in structure of the guard cell nucleus has been observed also by Mr. IMAMURA in the open stomata in Zebrina pendula immersed in water (verbal information). 
of an apparent nature due to the lack of sufficient difference in refractive index between the chromonemata and karyolymph to make them distinct enough. In the nucleus of Type 2, too, the same is the case. But the difference between these two types 2 and 4 is found in this that in the former, the lack of difference in the refractive index is due to the hydration of the chromonemata, while in the latter it is due to the dehydration, especially that of the karyolymph.1)

The guard cell nucleus in the open stoma frequently shows the chromonemata with a certain distinctness in the medium of liquid paraffin. In the hypotonic solutions, the chromonemata become more clearly visible. This nucleus may be regarded as of an intermediate type between Types 3 and 4 .

The descriptions given above are based on the results obtained by observation made with the bright field illumination. In the darkfield illumination with the cardioid condenser, the homogeneous nucleus is, as a rule, hardly bright except for the nuclear membrane and the contour of the nucleolus, and the nucleus showing distinct chromonemata in it in the ordinary illumination appears to be filled with a larger number of minute bright granules (cf. KUWADA and NAKAMURA, 1934, b), though the intensely bright cell wall and cell inclusions often preclude observers from the critical observation of the nuclear structure.

It must be also noted here that the interphasic nucleus differs from the resting nucleus in no point of importance so far as the hydration and dehydration experiments are concerned.

In connection with the results of experiments given above some few lines may be added about the changes in the structure of the guard cell nuclei which take place in association with the stomatal movement. In his study of the stomata in Vicia faba, WEBER (1927) has found that in the stomatal movement a "Sol-Gel-Umwandelung" takes place in the guard cell nuclei. This phenomenon is very interesting from the view point that the nuclear appearance may change in a close association with the change in the physiological functions of the cell. In connection with the present investigation the phenomenon was re-observed in Vicia faba, and the result was confirmed further in Tradescantia virginica, Zebrina pendula and Rhoeo discolor. In these plants, the nuclei of the guard cells are shrunken and highly light-refractive in the fully open state of the stomata, but in the closed state, they are swollen and transparent. In both open and closed states it is rather of general occurrence that a distinct struc-

1) The case reported by KAMNEv (1934) of the nuclei of the intestinal cpithelium (amphibia) seems to belong to our Type 4, because these nuclei show a distinct structure when treated with a hypotonic solution. 
ture or often even any structure is hardly visible in the nuclei. As has been already described above, the characteristic feature of the nucleus, observed in the open stomata can be obtained by applying a hypertonic solution to the nuclei in closed stomata and that observed in the closed stomata by immersing open stomata in a hypotonic solution. ${ }^{1)}$ During these transferring changes from one appearance to the other the nuclei exhibit as a transitory occurrence a distinct chromonema structure which is exhibited in the natural condition in the half-open stomata. According to WEBER, the nucleus is in a gel state in the open stomata, while it is in a sol state in the closed stomata. He is of the opinion that the changes in the nuclear appearance ("Sol-Gel-Umwandelung") occuring associated with the stomatal movement is due to the change in the $\mathrm{H}$-ion concentration in the guard cells. SAYre (1926), SCARTH (1927) and PeKareK (1934) show, on the other hand, that the guard cell sap is more alkaline when the stomata are open than when closed. In fact, in closed stomata ammonia causes the nuclear structure to be visible. This is, however, not a direct effect of ammonia, but is considered to be of the result of dehydration of the nuclear substance caused by the swelling of cell sap colloid due to the action of ammonia (cf. SCARTH, 1927). We are at present led to the conclusion that as shown by the results of the experiments we obtained with hyper- and hypotonic sugar solutions, the change in appearance of the nucleus is due to the hydration or the dehydration of the nuclear substance. The well known fact that the osmotic value of the guard cells of open stomata is much higher than that of the cells of closed stomata is in favour of this conclusion (cf. ILJIN, 1915, WIGGANs, 1921). In the open stomata the nucleus will lose its water, as the surrounding cytoplasm has a higher osmotic value than that of the nucleus, but in the closed stomata, the osmotic relation between the nucleus and cytoplasm being reversed, the nucleus will absorb a considerable amount of water from the cytoplasm, thus the nuclear substance is dehydrated in the former and hydrated in the latter.

The disappearance of the nucleolus in the guard cell which WEBER (1925) has observed in open stomata in Dahlia seems to represent the case of the nucleolus in the leaf epidermis in Elodea or the nucleolus in the closed stoma in Dahlia variabilis, where it disappears or becomes indistinct when put in a hypertonic solution.

Finally the result of experiments we obtained with heteropycnotic bodies may briefly be given below. While in the majority of cases the heterogeneous nucleus (Type 3 ) appears to be of a uniform chro-

1) In the latter change, probably, catatonosis plays a rôle. 
monema structure, in some other cases such as in Triturus pyrrhogaster (intestinal epithelium), Cucurbita pepo var. Toonas (hairs of the leaf), Nuphar japonicum var. crenatum (epidermis of the leaf) and Rhoeo discolor (do.), the nucleus shows one or several large chromatic lumps in the living state which may be identified with those structures known as the net-knots or the chromocenters. They differ from the nucleolus in this that they are positive to FEULGEN's nucleal staining to which the latter is negative (cf. HEITZ, 1932, KAMNEV, 1934). While in plants they disappear only in hypertonic solutions, and not in hypotonic solutions owing to a limited penetration of water caused by the cell wall pressure, in animal cells they can disappear in both hyper- and hypotonic solutions. The behaviour of these lumps towards the hyper- and hypotonic solutions shows, therefore, a marked resemblance to that of the chromonemata in the resting nucleus (in plants and animals) and that of the giant chromosomes in the salivary gland nucleus of Chironomus. It seems, thus, highly probable that these chromatic lumps, or the net-knots or the chromocenters, represent the heteropycnotic parts of chromosomes, or the whole of such chromosomes, or masses or aggregates of these. In order to prove this view experimentally, an artificial unravelling of these chromatic lumps was attempted (cf. KUWADA and NAKAMURA, 1934, a). The nuclei of Triturus and Nuphar were treated for several minutes with a $0.5 \mathrm{~N}$. solution of $\mathrm{NH}_{4} \mathrm{Cl}$, instead of the ammonia vapour originally used by KUWADA and NAKAMURA or KCN with which OURA (1936) has also obtained successful results, and were then stained with acetocarmine. The chromatic lumps were unravelled to so great an extent that we could no longer recognize the large chromatic lumps but only small remnant granules (compare Fig. 17 with Fig. 18). From this result of experiments it seems now clear that the chromatic lumps which are identifiable with the net-knots or the chromocenters are the structures representing the heteropycnotic chromosome parts or wholes, or aggregates of these bodies ("Sammelchromozentren"), whichever they may be, those remaining not unravelled in the telophase, or those secondarily brought to the compact state again. The view of HEITZ (1929 and 1932) and KUHN (1929), that the chromocenters are certain portions of chromosomes which are in the condensed state even in the resting nucleus, is in accord with the results of the experiments mentioned above.

\section{Conclusion}

In respect to the colloidal state of the resting nucleus in which the distinct structure is hardly perceptible in its healthy condition, we have two conflicting opinions. While StrugGer (1930), GRAY 
(1931) and some other authors are inclined to the view that such a nucleus is in the homogeneous sol state, that is, the state in which the chromatin particles disperse homogeneously in the karyolymph, Martens (1927), Sakamura (1927), Němec (1929), Fuji (1931), KuWada and Nakamura (1934, b), Morita (1935), Zeiger (1935), STroHMEYer (1935), KUWAdA (1936) and others have advocated the view that the optical homogeneity of the nucleus is merely a seeming one, the reticulate or the chromonema structure being maintained without undergoing any fundamental change. The main ground on which the former view is based is the less viscous consistency of the nuclear substance which is concluded from the results of micro-dissection experiments (CHAMBER, 1924), or indicated by the Brownian movement of the suspended particles (LEPESCHKIN, 1925, STRUGGER, 1930) or the movement of the nucleolus, taking place in the nuclear substance (GRAY, 1931, Linsbauer, 1932). But the result of the experiments with hypo- and hypertonic solutions showing that in the salivary gland chromosomes of Chironomus the chromatic bands of the chromosome can retain their original positions in the chromosome even in the case where the nucleus is brought to a quite homogeneous, and fluid condition as indicated by the Brownian movement taking place, favours the view that the low viscosity of the nuclear substance does not necessarily mean the true homogeneity of the nuclear colloid. Moreover, the results we obtained, (1) that the homogeneous nucleus II (Type 2) and the homogeneous nucleus III (Type 4) are rendered heterogeneous merely by dehydration and hydration respectively, (2) that the heterogeneous nucleus (Type 3 ) is transferred into the homogeneous nucleus II (Type 2) by hydration and into the homogeneous nucleus III (Type 4) by dehydration, (3) that these changes are quite reversible, and (4) that the nucleus of the guard cells of stomata undergoes marked changes in association with the osmotic changes in the cells, lead us to the conclusion that the homogeneity of the nuclei, whichever the type may be, the homogeneous nucleus II or the homogeneous nucleus III, is only an apparent one due to the refractive index of the chromonemata being so close to that of the karyolymph as to render them invisible. In the present investigation no case has been found where the homogeneity of the nucleus implies no state other than the homogeneous sol. The homogeneous nucleus I (Type 1), which, contrary to the homogeneous nucleus II (Type 2), presents no distinct structure during the course of the dehydration, may be regarded as one being in such a homogeneous sol state. But we have observed in Elodea that both the homogeneous nucleus I and the homogeneous nucleus II, and also the heterogeneous nuclei (Type 3) are found all together 
in a single leaf even in company with a number of the nuclei which may be regarded as representing the intermediate type between Type 1 and Type 2. From this fact it seems unlikely that the difference between the homogeneous nucleus I (Type 1) and the homogeneous nucleus II (Type 2) is of a fundamental nature, but it seems that it is rather a question of degree. In both cases, the chromonemata must be hydrated at least to such an extent that little difference in refractive index is shown between them and the karyolymph. But the hydration degree may be different between the two cases, so that in the case of the homogeneous nucleus $\mathrm{I}$, the chromonemata and the karyolymph are dehydrated with equal ease, and therefore, no marked difference in refractive index is produced between them, hence no structure is presented during the course of the dehydration, while in the homogeneous nucleus II, the chromonemata lose water more easily on dehydration than the karyolymph, and therefore, the chromonemata become more light refractive than the karyolymph, hence a heterogeneous structure becomes visible. The difference in the ease of dehydration may thus be regarded as that which distinguishes the two nuclei, and no fundamental structural difference seems to exist between them.

The tentative conclusion which we can draw from the results of the present investigation may be briefly stated as follows:

The essential components of the resting or metabolic nucleus are the chromonemata and the karyolymph. When the chromonemata are evenly hydrated throughout the whole length, the nucleus may be apparently homogeneous (the homogeneous nucleus I and the homogeneous nucleus II), but if all other short segments or portions remain less hydrated so as to present the pearl necklace structure throughout the whole length of the chromonemata, the whole nucleus will appear to be of a granular structure. If in the resting stage, certain parts of chromonemata or the whole of them are in a compactly coiled state, or several such chromonemata (chromosomes) come together to form a large compact mass, they may be regarded as the net-knots or chromocenters of various sizes. The distinct chromonemata are visible only when they are in a more dehydrated state evenly throughout the whole length than the karyolymph (the heterogeneous nucleus, Type 3 ). If the nuclear dehydration is more pronounced in degree, the nuclear structure is rendered again obscure, owing to the fact that the refractive index of the karyolymph approaches that of the chromonemata (the homogeneous nucleus III).

In no fundamental point does the so-called interphasic nucleus differ from the resting or metabolic nucleus, and the conclusion is the same for the former as for the latter. 


\section{Summary}

1) The treatments of various plant and animal cell nuclei with hypo- and hypertonic solutions show that the healthy or intact nuclei can be classified into four types according to the behaviour of the morphological components of the nucleus towards hydration or dehydration. In all these nuclei the essential components are the chromonemata which assume a loosely winding form giving the reticulate appearance to the general view of the nucleus or a compactly coiled form appearing as the net-knots or chromocenters, and the karyolymph. The optical homogeneity of the intact nuclei is due to the lack of difference in the refractive index between the two components, the chromonemata and the karyolymph.

2) The salivary gland nuclei of the Chironomus larvae are found to belong to Type 3 of our classification. When they are observed in the medium of liquid paraffin, several giant chromosomes which are of a banded structure are observed. When treated with a hypotonic solution, the chromosomes swell markedly and the chromatic bands are transformed into a necklace structure or rows of granules which disappear by further hydration. When these swollen nuclei are dehydrated, the chromatic bands reappear in the original positions in the chromosomes.

3) The hydration and dehydration experiments made with the guard cell nuclei of stomata in several plants show that these nuclei undergo marked changes in appearance responding to the osmotic pressures of the solutions applied. The same changes can be observed also in the natural state in close connection with the functional changes taking place in the guard cells.

4) The net-knots or the chromocenters which in some plants and animals are observable in the living nucleus can be experimentally transformed into a loose mass of uncoiled chromonemata. They may, therefore, be regarded as representing the parts of chromosomes in heteropycnosis or complete chromosomes in the same condition, or aggregates of these, in all of which the chromonemata remain more or less tightly coiled, instead of being in the loosely and irregularly coiled state.

It is a great pleasure to the writer to take this opportunity of expressing his sincere gratitude to Prof. Y. KUWADA under whose kind guidance and direction the present investigation was carried out.

\section{Literature Cited}

Bělař, K. (1930) : Beiträge zur Kausalanalyse der Mitose. III. Ztschr, f. Zellforsch. u. mikrosk. Anat., Bd. 10. 
Chambers, R. (1924): The physical structure of protoplasm as determined by microdissection and injection. Cowdry's General Cytology. Chicago.

Doyle, W. L. and C. W. Metz. (1985): Structure of the Chromosomes in the Salivary Gland Cells in Sciara (Diptera). Biol. Bull., Vol, 64.

Fujii, K. (1931): Cytology in the Past and Present (Japanese). Iwanami-Koza.

- and K. Yasui. (1936) : Cell Structure and Cell Division (Japanese). Hattori Hokokai Kenkyushoroku, II.

Gray, J. (1931): Experimental Cytology. Cambridge.

Heitz, E. (1929): Heterochromatin, Chromocentren, Chromomeren. Ber. d. D. Bot. Ges., Bd. 47.

- (1932): Die Herkunft der Chromocentren. Planta, Bd. 18.

Iljin, W.S. (1915): Die Regulierung der Spaltöffnungen im Zusammenhang mit der Veränderung des osmotischen Druckes. Beih. Bot. Centralbl., (I). Bd. 32.

Kamnev, J. E. (1934): Der Einfluß von Hypo- und Hypertonischen Lösungen auf die Struktur und Vitalfärbung der Epithelzellen des Amphibiendarmes (Rana temporaria, Triton taeniatus). Proroplasma, Bd. 21.

Kuhn, E. (1929): Die Beziehung der Chromocentren zur Chromosomenbildung. Ber. d. D. Bot Ges., Bd. 47.

Kuwada, Y. (1932): The Life-cycle of Chromosome. (Japanese). Kagaku, Vol. 2.

- (1936): On the Structure of the Cell Nucleus. (Japanese). Ztschr. d. Jap. mikrobiol. Ges., Bd. 30.

Kuwada, Y. and T. Nakamura, (1933): Behaviour of Chromonemata in Mitosis. I. Mem. Coll. Sci., Kyoto Imp. Univ. Ser. B., Vol. 9.

- (1934 a): Behaviour of Chromonemata in Mitosis. II. Cytologia, Vol. 5.

- $(1934 \mathrm{~b})$ : Behaviour of Chromonemata in Mitosis. III. Mem. Coll. Sci., Kyoto Imp. Univ Ser. B., Vol. 9.

Lepeschkin, W. W. (1925): Morphologische Eigentümlichkeiten der roten Blutkörperchen im Lichte der Kolloidchemie. Biol. General., Vol. 1.

Linsbauer, K. (1927): Weitere Beobachtungen an Spaltöffnungen. Planta, Bd. 3.

- (1932): Kerne, Nucleolen und Plasmabewegungen in den Blasenzellen von Mesembryanthemum cristallium. Sitzber. d. Ak. d. Wiss. Wien, mathem.naturwiss. Kl. Abt. I., Bd. 141.

Martens P. (1927): Le Cycle du Chromosome somatique dans les Phanérogames. III. Cellule, Tom. 38.

Metz, C. W. (1935): Internal Structure of Salivary Gland Cbromosomes in Sciara. Jour. Hered., Vol. 26.

Morita, J. (1935): On the Structure of the Resting Nucleus. II. (Japanese). Proc. Japan. Assoc. Acad. Sci., Vol. 10.

Němec, B. (1929). Über Struktur und Aggregatzustand des Zellkerns. Protoplasma, Bd. 7.

Oura, G. (1936): A new Method of Unravelling the Chromonema Spirals. Ztschr. f. wiss. Mikr. Bd. 53.

Pekarek, J. (1934): Über die Aziditätsverhältnisse in den Epidermis und Schließzellen bei Rumex acetosa im Licht und im Dunkeln. Planta, Bd. 21.

Péterfi, T. und H. Kojima. (1936): Die Wirkung mikrurgischer Eingriffe auf den Ruhekern der Pflanzenzellen. Protoplasma, Bd. 25.

Sakamura, T. (1927): Chromosomenforschung an Friscbem Material. Protoplasma, Bd. 1.

Sayre, J. D. (1926): Physiology of Stomata of Rumex patientia. Dissertation (Ohio University).

Scarth, G. W. (1927): Stomatal Movement: Its Regulation and Regulatory Rôle. Protoplasma, Bd. 2.

Schiwago, P. (1926): Über die Beweglichkeit der Fadenstrukturen im lebenden "Ruhekerne" der Froschleukozyten. Biol. Zentralbl., Bd. 46.

Strohmeyer, S. (1935): Beiträge zur Experimentellen Zytologie. Planta, Bd. 24.

Strugger, S. (1930): Beitrag zur Kolloidchemie des pflanzlichen Ruhekernes. Protoplasma, Bd. 10. 
Teleżyński, H. (1930) : Le Cycle du Chromosome somatique. I. Acta Soc. Bot. Poloniae, Vol. 7.

Wada, B. (1935) : Mikrurgische Untersuchungen lebender Zellen in der Teilung. III. Cytologia, Vol. 7.

Weber, F. (1925) : Der Zellkern der Schließzellen. Planta, Bd. 1.

- (1927): Cytoplasma- und Kern-Zustandsänderungen bei Schließzellen. Protoplasma, Bd. 2.

Wiggans, R. G. (1921): Variations in the osmotic Concentration of the Guard Cells during the Opening and Closing of Stomata. Amer. Jour. Bot., Vol. 8.

Yamaha, G. und T. Ishii. (1932): Utber die Ionenwirkung auf die Chromosomen der Pollenmutterzellen von Tradescantia reflexa. I. Cytologia, Vol. 3.

Yasui, K. (1935): On the Structure of the Chromosome in the Salivary Gland Cell of Drosophila melanogaster. Cytologia, Vol. 6.

Zeiger, K. (1935): Zum Problem der vitalen Struktur der Zellkernes. Ztschr. f. Zellforsch. mikro. Anat., Bd. 22.

\section{Explanation of Plates}

\section{Plate 16}

All the photomicrographs were taken with a LEITZ's Makam using a LEITZ homog. imm. obj. 1/12 and a LeITz periplan oc. 8 .

Figs. 1, 2 and 3. The same piece of young leaf epidermis of Elodea densa (the nuclei, Type 1).

Fig. 1. Mounted with spring water. Photo. at $7.23 \mathrm{p} . \mathrm{m}$. Nuclei $a$ and $b$ are of the structure of the homogeneous nucleus 1 , and $d$ is a heterogeneous nucleus (Type 3). In $c$, a mitotic figure in metaphase is shown.

Fig. 2. In the medium of $0.5 \mathrm{~mol}$ sucrose solution in place of the spring water. Photo. at 7.30 p.m. Chromosomes and all the nuclear components are invisible.

Fig. 3. With the medium replaced again with spring water. Photo. at 7.40 p.m. The original appearance of the nuclei and the chromosomes are recovered.

Figs. 4, 5 and 6 . The same closed stoma in leaf epidermis of Tradescantia virginica (the nuclei, Type 2).

Fig. 4. In the medium of $0.2 \mathrm{~mol}$ sucrose solution. Photo. at $10.48 \mathrm{a} . \mathrm{m}$. Nuclei of the guard cells are hardly recognizable (the homogeneous nuclei II).

Fig. 5. In $0.8 \mathrm{~mol}$ sucrose solution. Photo. at $11.01 \mathrm{a.m}$. Chromonemata are visible in the nuclei (the heterogeneous nuclei).

Fig. 6. In $1.6 \mathrm{~mol}$ sucrose solution. Photo. at 11.32 a.m. The nuclei shrink and present no distinct structure (the homogeneous nuclei III).

Figs. 7, 8 and 9. The same piece of young petal epidermis of Tradescantia reflexa (the nuclei, Type III, a).

Fig. 7. In $0.05 \mathrm{~N}$. $\mathrm{NaCl}$ solution. Photo. at 9.40 a.m. Chromonemata are very distinct (the heterogeneous nuclei).

Fig. 8. In $0.5 \mathrm{~N}$. NaCl solution. Photo at $9.55 \mathrm{a} . \mathrm{m}$. The nuclei decrease in volume and increase in refractive index accompanied by disappearance of chromonemata (the homogeneous nuclei III).

Fig. 9. In di-distilled water. Photo. at $10.15 \mathrm{a} . \mathrm{m}$ The original apperance of the nuclei is recovered (the het 6 rogeneous nuclei).

\section{Plate 17}

Figs. 10,11 and 12. The same half-open stoma of Tradescantia virginica (the nuclei, Type III, $b$ ).

Fig. 10. In $0.4 \mathrm{~mol}$ glucose solution. Photo. at $10.00 \mathrm{a} . \mathrm{m}$. Chromonemata in the guard cell nuclei are very distinct (the heterogeneous nucleus). 

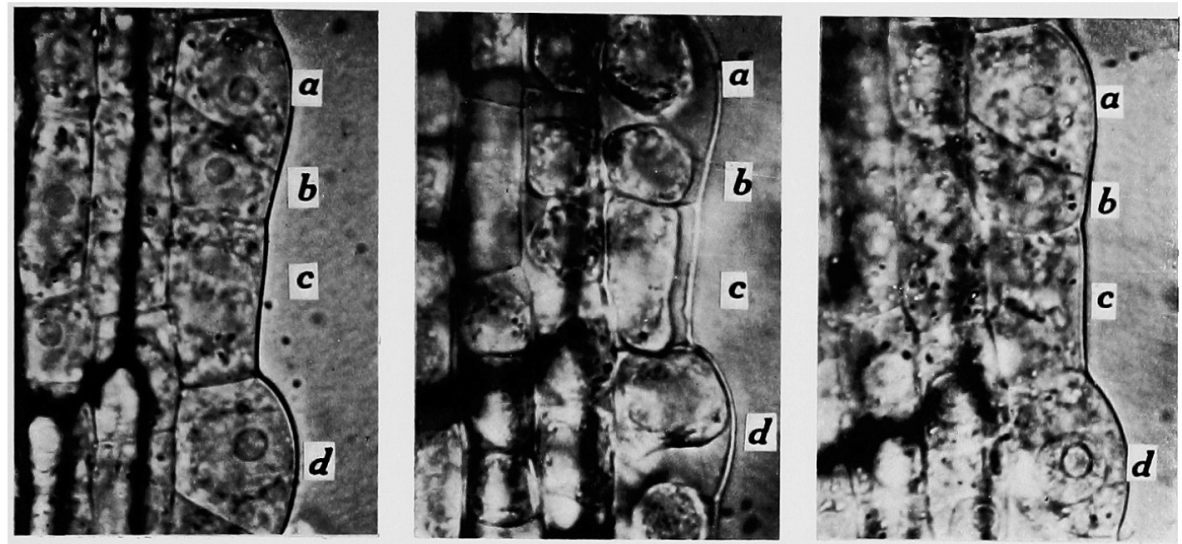

1

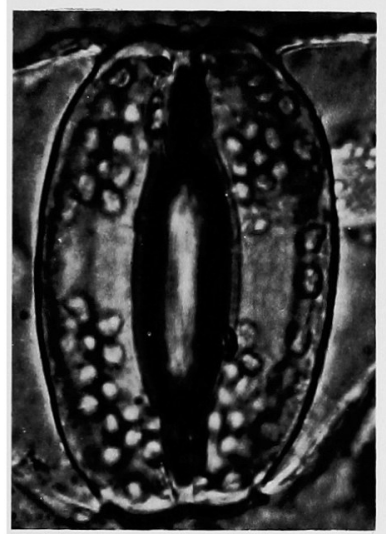

2

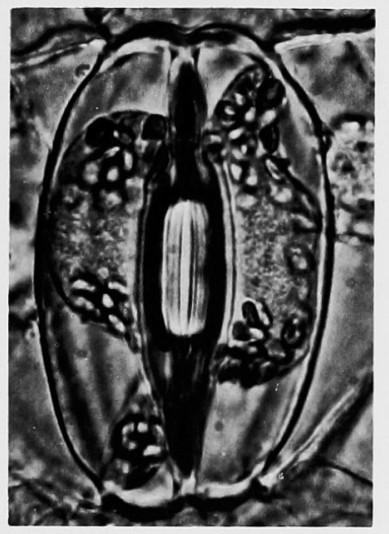

3

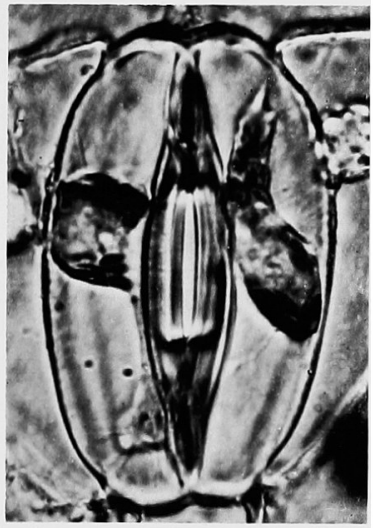

5

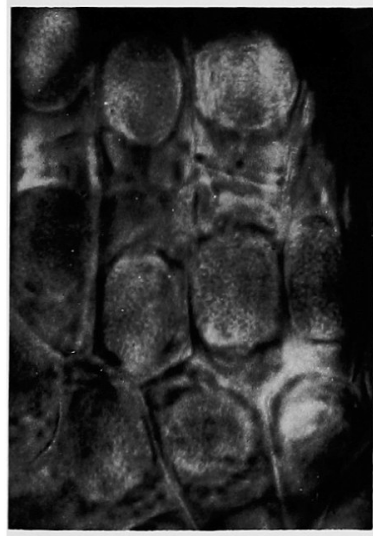

7

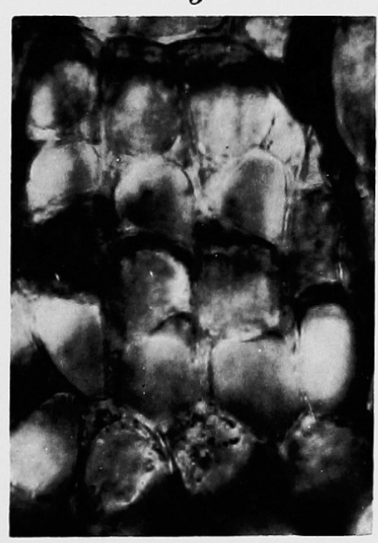

8

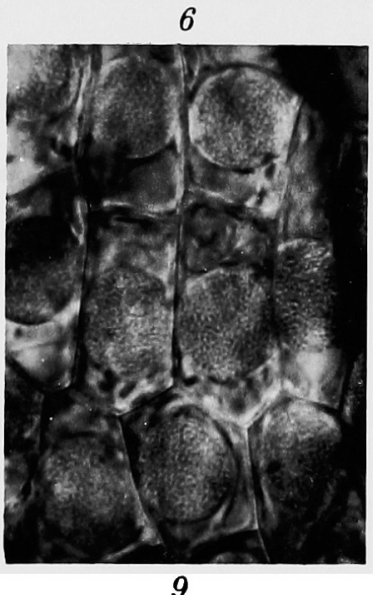

Shinke: An Experimental Study on the Structure of Living Nuclei in the Resting Stage 


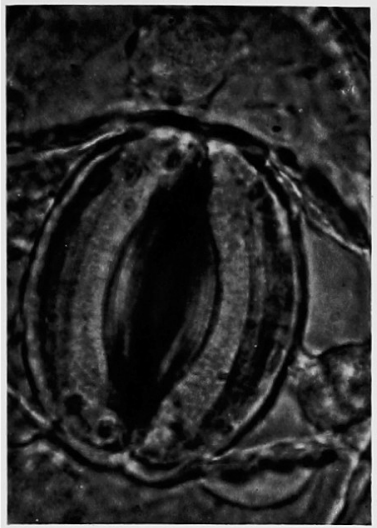

10

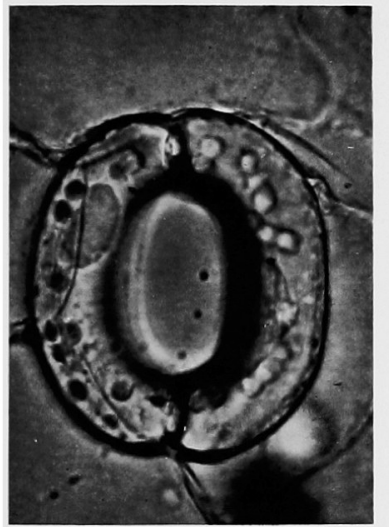

14

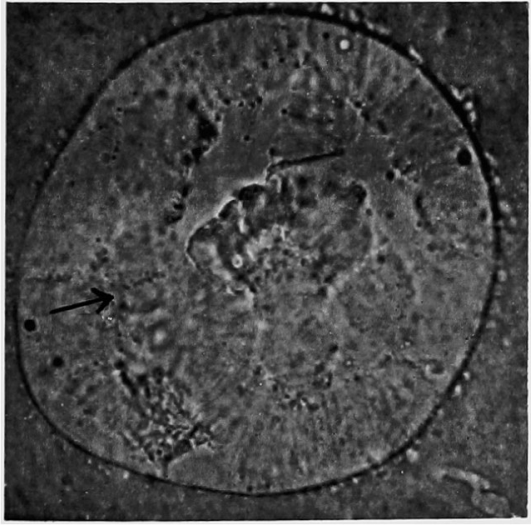

13

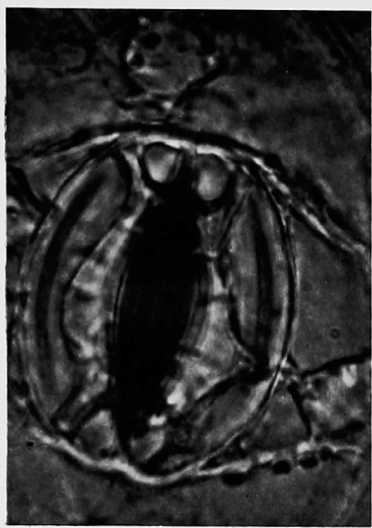

11

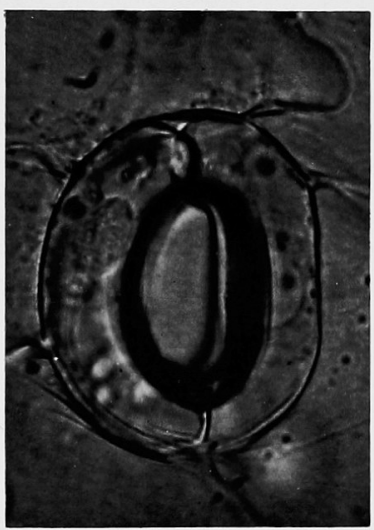

15

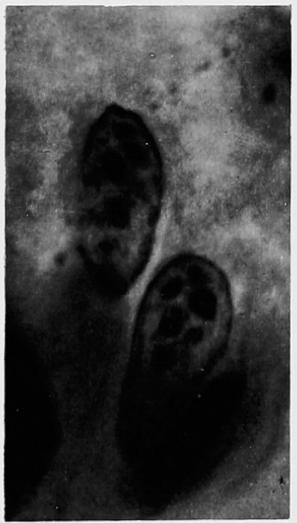

17

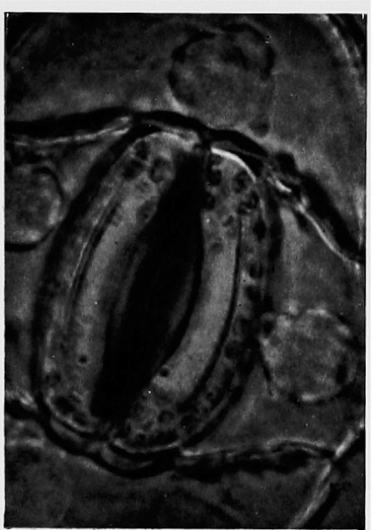

12

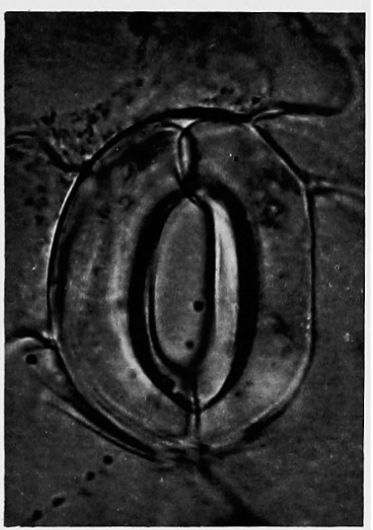

16

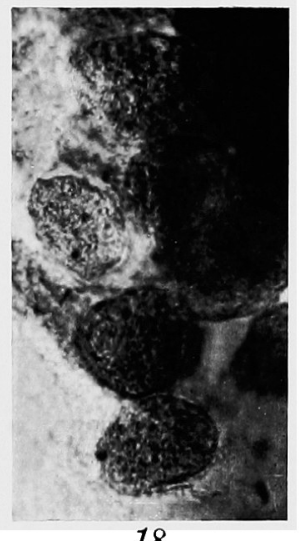

18

Shinke: An Experimental Study on the Structure of Living Nuclei in the Resting Stage 
Fig. 11. In $0.8 \mathrm{~mol}$ glucose solution, photo. at $10.05 \mathrm{a.m}$. The nuclei shrink and exhibit no distinct chromonemata (the homogeneous nuclei Ili).

Fig. 12. In di-distilled water, photo at $10.35 \mathrm{a} . \mathrm{m}$. The nuclei swell. The chromonemata are not visible. They were visible for a short time before photographing.

Fig. 13. A salivary gland cell nucleus of Chironomus dorsalis observed in a diluted RINGER's solution (containing ca. $0.33 \% \mathrm{NaCl}$ ). The arrow indicates chromatic granules in linear arrangement in the swollen chromosome.

Figs. 14, 15 and 16. The same fully-open stoma of Vicia faba (the nuclei, Type 4).

Fig. 14. In $0.5 \mathrm{~mol}$ solution of glucose. Photo. at $2.10 \mathrm{p} . \mathrm{m}$. Guard cell nuclei show no visible structure (the homogeneous nucleus III).

Fig. 15. In di-distilled water. Photo. at 2.15 p.m. The chromonemata are distinct (the heterogeneous nucleus).

Fig. 16. In the same medium. Photo. at $2.23 \mathrm{p.m}$. The nuclei are nearly homogeneous (the homogeneous nucleus II).

Figs. 17 and 18. Nuclei of intestinal epithelium of Triturus pyrrhogaster.

Fig. 17. From an ordinary acetocarmine preparation. Large netknots are shown.

Fig. 18. Stained with acetocarmine after treatment with $0.5 \mathrm{~mol}$ solution of $\mathrm{NH}_{4} \mathrm{Cl}$ for five mimutes. Large net-knots are no longer visible. 